\title{
Intratracheal administration of budesonide with surfactant in very low birth weight infants to prevent bronchopulmonary dysplasia
}

\author{
Minji $\mathrm{Heo}^{\oplus}$, Ga Won Jeon ${ }^{\oplus}$ \\ Department of Pediatrics, Busan Paik Hospital, Inje University College of Medicine, Busan, Korea.
}

\begin{abstract}
Background and objectives. Respiratory distress syndrome (RDS) is a major cause of early postnatal death in preterm infants. Bronchopulmonary dysplasia (BPD) is one of the most fatal chronic respiratory complications of preterm infants after management of RDS. Anti-inflammatory therapy with corticosteroid is one of the effective treatments to prevent BPD. However, systemic administration of corticosteroid is not recommended because of long-term adverse effects. We studied the effect of early intratracheal instillation of budesonide with surfactant in preterm infants with severe RDS.
\end{abstract}

Method. Very low birth weight infants (VLBWIs) weighing less than 1,500 g who were admitted to the neonatal intensive care unit (NICU) of Busan Paik Hospital between January 2018 and December 2018 and diagnosed with severe RDS were enrolled. The treatment group was given a mixture of budesonide and surfactant (calfactant) while the control group was given surfactant (calfactant) only.

Results. Surfactant re-dosing, duration of mechanical ventilation, BPD, mortality, and retinopathy of prematurity ( $\geq$ stage 2 ) were not different between the two groups though there were decreasing trends in the treatment group compared to those in the control group. The duration of hospital stay was longer in the control group with statistical significance.

Conclusion. Early intratracheal administration of budesonide with surfactant in preterm infants with severe RDS might decrease BPD and mortality without disturbing surfactant function. Further studies with different preparations of surfactants with a large number of preterm infants are required.

Key words: bronchopulmonary dysplasia, budesonide, preterm infant, pulmonary surfactant, respiratory distress syndrome.

Respiratory distress syndrome (RDS) is a major cause of early postnatal death in preterm infants. Bronchopulmonary dysplasia (BPD) is one of the most fatal chronic respiratory complications in preterm infants after management of RDS. The incidence of BPD has not decreased despite advances in neonatal care of RDS in the post-surfactant era. ${ }^{1} \mathrm{BPD}$ is a lung injury

$凶$ Ga Won Jeon

iamgawon@hanmail.net

Received 11th April 2019, revised 13th August 2019, accepted 29th August 2019.

This abstract was submitted to the 30th Annual Meeting of the European Society of Paediatric and Neonatal Intensive Care, Salzburg, Austria, June 18-21, 2019. syndrome. Its pathogenesis is multifactorial. Inflammation is an important pathogenetic factor in the development of BPD. ${ }^{2}$ Antiinflammatory therapy with corticosteroid is one of the most effective treatments to prevent BPD. ${ }^{3}$ However, systemic corticosteroid can cause long-term adverse effects such as poor somatic growth, small head circumference, and neurodevelopmental disabilities such as neuromotor deficits, and cognitive deficits. ${ }^{4}$ Thus, systemic administration of corticosteroid is not recommended. ${ }^{5}$

If corticosteroid can be used directly to lungs, then systemic adverse effects can be decreased and local anti-inflammatory effect can be 
increased. However, there have been limitations to deliver corticosteroid to distal lungs of newborn babies even if corticosteroid is inhaled as aerosol particles.

Budesonide is a strong corticosteroid with a local anti-inflammatory effect commonly used as a nebulizing suspension for treating bronchial asthma in children. ${ }^{6}$ However, inhalation of budesonide as aerosol particles with metered dose inhaler to newborn babies is technically difficult. Budesonide has to be deposited in lung tissues by inhalation. It needs to be successfully distributed to lung tissues and then dissolved in lung cells of newborn babies. Inhalation of budesonide to newborn babies has been shown to be ineffective because this method cannot deliver budesonide to distal lungs. ${ }^{7-9}$ Thus, an alternative lung-targeted delivery method is needed. Some researchers have studied intratracheal administration of budesonide. However, intratracheal administration of budesonide alone is ineffective in decreasing inflammation of lungs. ${ }^{10}$ One of the suggested methods to deliver budesonide to distal lungs is intratracheal administration of budesonide with vehicle.

Pulmonary surfactant is a mixture of phospholipids and surfactant proteins (SPs). ${ }^{11,12}$ Phospholipids bilayers incorporated with SPs are typical structures of surfactant. These layers called surface films play an important role in adsorption and spreading of surfactant into distal lungs with excellent solubility related to the rich lipid content that can lower surface tension. ${ }^{13}$ Intratracheal administration of drug with surfactant as a vehicle markedly facilitates the distribution and spreading of the drug compared to administration of the drug alone. ${ }^{14-16}$ Thus, surfactant has been suggested as a vehicle to deliver drugs to distal lungs. ${ }^{17}$ Huang et al. ${ }^{18}$ revealed that the administration of budesonide with surfactant can facilitate pulmonary distribution of budesonide compared to budesonide alone using fluorescent dye in mice. The objective of the present study was to determine the effect of early intratracheal instillation of budesonide with surfactant in preterm infants with severe RDS for alleviating BPD.

\section{Material and Methods}

The protocol of this study was reviewed and approved by the Institutional Review Board of Inje University Busan Paik Hospital (identification code: 19-0019) in accordance with the Declaration of Helsinki. A waiver of consent was granted for chart review without patient contact. Very low birth weight infants (VLBWIs) weighing less than 1,500 $\mathrm{g}$ who were admitted to the neonatal intensive care unit (NICU) of Busan Paik Hospital between January 2018 and December 2018 and diagnosed with severe RDS were enrolled. VLBWIs with severe RDS on chest radiography who required mechanical ventilator with fractional inspired oxygen $\left(\mathrm{FiO}_{2}\right)$ of $>0.5$ were included. VLBWIs with chromosomal abnormality, congenital cardiac anomaly, or congenital pulmonary anomaly were excluded as these conditions could be confounding factors by interfering with pulmonary function and survival, making them unsuitable for evaluating the efficacy or safety of budesonide with surfactant. Included infants were allocated to two groups according to the medicine instilled: treatment group, surfactant and budesonide; and control group, surfactant only.

\section{Study protocol}

Clinical data were collected retrospectively from medical records. The diagnosis of RDS and the decision to perform surfactant replacement were left to the attending physician based on disease severity according to chest radiography and assisted ventilation. ${ }^{19}$

Surfactants were instilled into the trachea via an endotracheal tube using an orogastric tube. The treatment group was given a mixture of $0.25 \mathrm{mg} / \mathrm{kg}$ ( $1 \mathrm{~mL} / \mathrm{kg}$ ) of budesonide (Pulmicort nebulizing suspension, Astra Zeneca, Lund, Sweden) and $105 \mathrm{mg} / \mathrm{kg}(3 \mathrm{~mL} / \mathrm{kg})$ of calfactant (Infasurf®, ONY, Inc., Amherst, NY, USA) while the control group was given $105 \mathrm{mg} /$ 
$\mathrm{kg}$ of calfactant only. The concentration ratio of calfactant to budesonide was $35 \mathrm{mg}$ : 0.25 $\mathrm{mg}$ or 140:1. The dosage of budesonide was determined according to previous studies. ${ }^{20,21}$

Infant demographic factors included gestational age, birth weight, gender, small for gestational age (SGA), Apgar score, and clinical risk index for babies (CRIB) II score. Maternal demographic factors included antenatal corticosteroids therapy, maternal gestational diabetes mellitus (GDM), maternal pregnancy-induced hypertension (PIH), and histologically confirmed chorioamnionitis. Outcomes associated with BPD included doses of surfactant, total duration of mechanical ventilation, duration of invasive ventilation, BPD, severity of BPD, and mortality. Outcomes associated with prematurity included patent ductus arteriosus (PDA), high grade intraventricular hemorrhage (IVH, $\geq$ grade 3$)$, periventricular leukomalacia (PVL), high stage retinopathy of prematurity (ROP, $\geq$ stage 2 ), necrotizing enterocolitis (NEC, $\geq$ stage 2 ), and duration of hospital stay.

SGA was defined as a birth weight less than the tenth percentile on fetal-infant growth chart for preterm infants. ${ }^{22}$ BPD was defined as an oxygen dependency at 36 weeks post-menstrual age with oxygen treatment for at least the first 28 days of life. BPD was subdivided to three groups according to its severity: mild BPD, breathing room air at 36 weeks post-menstrual age or discharge; moderate $\mathrm{BPD}$, need for < $30 \% \mathrm{O} 2$ at 36 weeks post-menstrual age or discharge; and severe BPD, need for $\geq 30 \%$ O2 with or without positive pressure ventilation or continuous positive pressure at 36 weeks postmenstrual age or discharge. ${ }^{23}$ Sepsis was limited to positive blood culture with clinical signs of systemic infection. ${ }^{24}$

\section{Statistical analysis}

For nominal variables, Chi-square test or Fisher's exact test was performed. For continuous variables, Student's $t$-test or Mann-Whitney $U$ test was performed. All statistical analyses were performed using SAS Enterprise Guide 3.0 (SAS Institute, Cary, NC, USA). $P$-values $<0.05$ were considered significant. Data are given as mean \pm standard deviation.

\section{Results}

\section{Demographic factors}

Among a total of 68 VLBWIs who were admitted to the NICU of Busan Paik Hospital during the period of enrollment (January 2018 through December 2018), 34 VLBWI who were diagnosed as severe RDS were enrolled: 16 in the treatment group (budesonide + surfactant) and 18 in the control group (surfactant). There were no significant differences in gestational age, birth weight, gender, SGA, Apgar score at 1 and 5 minutes, CRIB II score, antenatal corticosteroids, maternal GDM, maternal PIH, or chorioamnionitis between the treatment group and the control group (Table I).

Gestational age was $28^{+4} \pm 1^{+6}$ weeks (range: $25^{+2}$ - $32^{+0}$ weeks), and $28^{+2} \pm 2^{+0}$ weeks (range: $25^{+0}$ $33^{+4}$ weeks), and birth weight was $1055 \pm 247 \mathrm{~g}$ (range: $460-1400 \mathrm{~g}$ ), and $1032 \pm 255 \mathrm{~g}$ (range: $615-1400 \mathrm{~g})$ in treatment group and control group, respectively.

\section{$B P D$ and mortality}

Surfactant re-dosing was not different between the two groups (treatment group: 5 (31.3\%); control group: $8(44.4 \%) ; p=0.429)$ (Table II). Total duration of mechanical ventilation (treatment group: $14.7 \pm 15.7$ days; control group: $26.3 \pm 26.7$ days; $p=0.162$ ), and duration of invasive ventilation (treatment group: 10.6 \pm 13.2 days; control group: $19.0 \pm 25.2$ days; $p$ $=0.266$ ) were not different between the two groups, though there were decreasing trends in the treatment group compared to those in the control group (reduction of 11 days and 8 days, respectively).

The incidence of BPD, mortality rate, and BPD or death were not different between two groups. There were decreasing trends of BPD 
Table I. Demographic factors.

\begin{tabular}{|c|c|c|c|}
\hline & $\begin{array}{l}\text { Treatment group } \\
(\mathrm{n}=16)\end{array}$ & $\begin{array}{l}\text { Control group } \\
(\mathrm{n}=18)\end{array}$ & $\mathrm{p}$ value \\
\hline Gestational age, week ${ }^{+ \text {day }}$ & $28^{+4} \pm 1^{+6}\left(25^{+2}-32^{+0}\right)$ & $28^{+2} \pm 2^{+0}\left(25^{+0}-33^{+4}\right)$ & 0.641 \\
\hline Birth weight, g & $\begin{array}{l}1055 \pm 247 \\
(460-1400)\end{array}$ & $\begin{array}{l}1032 \pm 255 \\
(615-1400)\end{array}$ & 0.791 \\
\hline Male, n (\%) & $8(50.0)$ & $9(50.0)$ & 1.000 \\
\hline SGA, n (\%) & $4(25.0)$ & $5(27.8)$ & 0.855 \\
\hline Apgar score at $1 \mathrm{~min}$ & $4.25 \pm 1.53$ & $4.44 \pm 1.65$ & 0.725 \\
\hline Apgar score at $5 \mathrm{~min}$ & $6.81 \pm 1.05$ & $6.67 \pm 1.19$ & 0.708 \\
\hline CRIB II & $7.50 \pm 2.71$ & $7.56 \pm 2.77$ & 0.953 \\
\hline Antenatal corticosteroids, n (\%) & $16(100.0)$ & $18(100.0)$ & \\
\hline Maternal GDM, n (\%) & $0(0)$ & $2(11.1)$ & 0.169 \\
\hline Maternal PIH, n (\%) & $3(18.8)$ & $1(5.6)$ & 0.233 \\
\hline Chorioamnionitis, n (\%) & $7(43.8)$ & $5(27.8)$ & 0.331 \\
\hline
\end{tabular}

SGA: small for gestational age, CRIB: clinical risk index for babies, GDM: gestational diabetes mellitus, PIH: pregnancy induced hypertension.

Table II. Bronchopulmonary dysplasia and mortality.

\begin{tabular}{llll}
\hline & $\begin{array}{l}\text { Treatment group } \\
(\mathrm{n}=16)\end{array}$ & $\begin{array}{l}\text { Control group } \\
(\mathrm{n}=18)\end{array}$ & p value \\
\hline Surfactant re-dosing, $\mathrm{n}(\%)$ & $5(31.3)$ & $8(44.4)$ & 0.429 \\
Total duration of mechanical ventilation, days & $14.7 \pm 15.7$ & $26.3 \pm 26.7$ & 0.162 \\
Duration of invasive ventilation, days & $10.6 \pm 13.2$ & $19.0 \pm 25.2$ & 0.266 \\
BPD, $\mathrm{n}(\%)$ & $5(33.3)$ & $8(53.3)$ & 0.269 \\
BPD (moderate to severe), $\mathrm{n}(\%)$ & $2(13.3)$ & $4(26.7)$ & 0.361 \\
BPD (severe), $\mathrm{n}(\%)$ & $0(0.0)$ & $2(13.3)$ & 0.143 \\
Death, $\mathrm{n}(\%)$ & $1(6.3)$ & $4(22.2)$ & 0.189 \\
BPD or death, $\mathrm{n}(\%)$ & $6(37.5)$ & $11(61.1)$ & 0.169 \\
\hline
\end{tabular}

BPD: bronchopulmonary dysplasia.

(treatment group: 33.3\%; control group: 53.3\%; $p=0.269$ ), mortality rate (treatment group: 6.3\%; control group: $22.2 \% ; p=0.189)$, and BPD or death (treatment group: $37.5 \%$; control group: $61.1 \% ; p=0.169)$. However, we couldn't find statistical differences.

There was no severe BPD in the treatment group whereas $13.3 \%$ had severe BPD in the control group

\section{Outcomes Associated with Prematurity}

Incidences of ligation of PDA, high grade IVH ( $\geq$ grade 3 ), PVL, and NEC ( $\geq$ stage 2 ) were similar between the two groups (Table III).
Incidence of high stage ROP ( $\geq$ stage 2 ) was not different between the two groups, though there was a decreasing trend in the treatment group compared to the control group (treatment group: $12.5 \%$; control group: $33.3 \%$; $p=0.166$ ). The duration of hospital stay was longer in the control group with statistical significance (treatment group: $73.2 \pm 19.5$ days; control group: $91.9 \pm 20.3$ days; $p=0.018$ ).

\section{Discussion}

Budesonide has a structure similar to cholesterol, a sterol component of mammalian cell membrane. Thus, budesonide is lipid 
Table III. Outcomes associated with prematurity.

\begin{tabular}{llll}
\hline & $\begin{array}{l}\text { Treatment group } \\
(\mathrm{n}=16)\end{array}$ & $\begin{array}{l}\text { Control group } \\
(\mathrm{n}=18)\end{array}$ & p value \\
\hline Ligation of PDA, $\mathrm{n}(\%)$ & $1(6.3)$ & $3(16.7)$ & 0.347 \\
IVH $(\geq$ grade 3), $\mathrm{n}(\%)$ & $1(6.3)$ & $1(5.9)$ & 0.965 \\
PVL, n $(\%)$ & $1(6.3)$ & $0(0.0)$ & 0.295 \\
ROP $(\geq$ stage 2), n (\%) & $2(12.5)$ & $5(33.3)$ & 0.166 \\
NEC ( $\geq$ stage 2), $\mathrm{n}(\%)$ & $0(0.0)$ & $0(0.0)$ & $0.018^{*}$ \\
Hospital stay, days & $73.2 \pm 19.5$ & $91.9 \pm 20.3$ & \\
\hline
\end{tabular}

PDA: patent ductus arteriosus, IVH: intraventricular hemorrhage, PVL: periventricular leukomalacia, ROP: retinopathy of prematurity, NEC: necrotizing enterocolitis.

${ }^{*} p$-values $<0.05$.

soluble. It has strong affinity to airway and lung tissues. After budesonide is absorbed in lung tissue, it can conjugate with fatty acid and make fatty acid esters of budesonide. This conjugated form of budesonide is lipophilic, thus prolonging intracellular retention with very slow release of free budesonide. Other corticosteroids such as fluticasone propionate or beclomethasone dipropionate could not make fatty acid esters, which is why budesonide has longer pharmacological effects in airway tissues than other corticosteroids. ${ }^{25,26}$ This is also the reason why topically inhaled budesonide has markedly better uptake and retention in airway tissues than non-inhaled type of corticosteroid.

We calculated the dosage of budesonide according to a previous study reporting that if the concentration ratio of surfactant and budesonide was 50:1 or more, then budesonide would not disturb the role of surfactant to decrease surface tension. ${ }^{20}$ Therefore, calfactant $(105 \mathrm{mg} / \mathrm{kg}, 35 \mathrm{mg} / \mathrm{ml})$ and budesonide $(0.25$ $\mathrm{mg} / \mathrm{kg}, 0.25 \mathrm{mg} / \mathrm{ml}$ ) at a concentration ratio of $35 \mathrm{mg}: 0.25 \mathrm{mg}$ or 140:1 (>50:1) was chosen so that surfactant function would not be disturbed by budesonide.

Systemically administered corticosteroid can cross the blood brain barrier and result in high concentrations in brain tissues, especially in hippocampus which contains high density of corticosteroid receptors. ${ }^{3}$ Corticosteroid in brain tissues can change cerebral blood flow abnormally. It can cause ischemia and exert adverse effects on brain growth, especially in the hippocampus which is a critical area for memory and learning. This is why systemic administered corticosteroid can cause neurodevelopmental side effects.

To improve the local effect and decrease the systemic side effect of steroid, another route of drug delivery has been studied. Shah et al. ${ }^{27-}$ ${ }^{29}$ have reviewed the effect of inhaled versus systemic corticosteroids in preterm infants to prevent BPD with meta-analysis over three times. There were differences between study protocols. However, most trials administered inhaled budesonide or beclomethasone dipropionate by metered dose inhaler and a spacer device or intravenous dexamethasone. They found that there were no significant differences in effectiveness or side effects between inhaled and systemic corticosteroids. All reviewed randomized controlled trials did not use surfactant as a vehicle. They administered inhaled corticosteroid with metered dose inhaler, a well-known ineffective delivery system of drugs to the airway and lung in preterm infants. They suggested that a better mode of delivering inhaled corticosteroid could be more effective without increasing side effects.

Researchers have investigated intratracheal administering steroid with surfactant as a vehicle in animal models. Fajardo et al. ${ }^{30}$ have revealed that intratracheal instillation of budesonide with surfactant is more effective than intratracheal 
budesonide alone or inhaled budesonide in ventilated rabbit. Chen et al. ${ }^{31}$ have administered intratracheal high dose dexamethasone $(0.5 \mathrm{mg} /$ $\mathrm{kg}$ ) with surfactant (beractant, $50 \mathrm{mg} / \mathrm{kg}$ or 100 $\mathrm{mg} / \mathrm{kg}$ ) in rats with acute lung injury. They concluded that intratracheal administration of high dose dexamethasone with surfactant could alleviate inflammation of lungs compared to intratracheal administration of surfactant alone. In another animal study with rats, intratracheal administered low dose dexamethasone (0.04 $\mathrm{mg} / \mathrm{kg}, 1 \mathrm{~mL} / \mathrm{kg}$ ) with surfactant as a vehicle (beractant, $10 \mathrm{mg} / \mathrm{kg}$, $5 \mathrm{~mL} / \mathrm{kg}$, diluted to $2 \mathrm{mg} /$ $\mathrm{mL}$ )improved the distribution of dexamethasone to peripheral lungs compared to the use of saline as a vehicle. It also decreased circulating concentration of dexamethasone compared to systemic administration of dexamethasone. ${ }^{32}$ They suggested that the most effective mode of delivering corticosteroid could be intratracheal instillation. Yang et $\mathrm{al}^{33}$ have reported that intratracheal administered budesonide $(0.5 \mathrm{mg} /$ $\mathrm{kg}$ ) with surfactant (beractant, $100 \mathrm{mg} / \mathrm{kg}$ ) in neonatal piglets can improve oxygenation and histological lung injuries during acute period (in four hours) compared to no treatment, although it has no difference compared to treatment with surfactant alone. However, budesonide did not disturb surfactant function of decreasing surface tension. They reported updated results ${ }^{34}$ that intratracheal administration of budesonide $(0.25 \mathrm{mg} / \mathrm{kg}$ ) with surfactant (beractant, $100 \mathrm{mg} /$ $\mathrm{kg}$ ) in neonatal piglets with severe RDS could improve oxygenation and histological lung injuries over 24 hours constantly. Differences from their previous study were suggested by too short observation periods such as four hours to alleviate oxygenation and histological changes. Considering that BPD is a lung injury syndrome with chronic and multifactorial pathogenesis, observation over a longer period might be more reliable for evaluating the effectiveness of drugs to alleviate BPD.

In another study by Ricci et al. ${ }^{10}$, intratracheal administration of $0.25 \mathrm{mg} / \mathrm{kg} \quad(1 \mathrm{~mL} /$ $\mathrm{kg}$ ) budesonide with $200 \mathrm{mg} / \mathrm{kg}(2.5 \mathrm{~mL} /$ $\mathrm{kg}$ ) surfactant improved tidal volume, gas exchange, and lung compliance in premature rabbits. They used poractant alfa as a vehicle, not beractant. The concentration ratio of poractant alfa to budesonide was $80 \mathrm{mg}: 0.25 \mathrm{mg}$ or 320:1 ( $\geq 50: 1$ ). Thus, surfactant function might not be disturbed by budesonide. Also, administration of budesonide with surfactant decreased lung inflammation compared to budesonide or surfactant alone. This meant that budesonide did not disturb surfactant function, and surfactant can be a good vehicle to deliver budesonide to distal lungs to alleviate BPD. Roberts et al..$^{35}$ have reported that, when budesonide with surfactant is administered intratracheally in premature lambs, budesonide and its metabolites (16 $\alpha$-hydroxy prednisolone, or budesonide-palmitate) could not be detected in the brain tissue. This means that intratracheally administered budesonide with surfactant is deposited in the airway and lung tissues mostly. It is less absorbed systemically, showing low plasma concentration. It could not cross the blood brain barrier, resulting in minimal neurologic side effects with only local anti-inflammatory effect in airway tissue

Yeh et al. ${ }^{20}$ have conducted a prospective randomized controlled trial (RCT) with intratracheal instillation of $0.25 \mathrm{mg} / \mathrm{kg}(1 \mathrm{~mL} /$ $\mathrm{kg}$ ) budesonide with $100 \mathrm{mg} / \mathrm{kg}$ (4 mL/kg) surfactant (beractant) in 116 VLBWIs with severe RDS. They reported that this therapy could decrease the incidence of BPD and mortality and increase survival without BPD compared to surfactant only therapy without significantly increasing adverse events. In a follow up study ${ }^{21}$ of this trial at the age of two to three years of these enrolled preterm infants (67 VLWBIs, 35 budesonide treated and 32 control), there were no significant differences in the incidence of hospital admission by respiratory causes or physical growth such as body weight, height, or head circumference between budesonide with surfactant treated group and surfactant only treated group. There were no significant differences in Mental Development Index (MDI) or Psychomotor Development Index (PDI) by Bayley Scales of Infant Development 
(BSID) II between budesonide with surfactant treated group and surfactant only treated group either. Authors concluded that there were no long-term adverse events associated with intratracheal instillation of budesonide with surfactant. In a prospective multicenter $\mathrm{RCT}^{36}$ 265 VLBWIs in three tertiary NICUs in USA and Taiwan were enrolled. Budesonide (0.25 $\mathrm{mg} / \mathrm{kg}, 1 \mathrm{~mL} / \mathrm{kg}$ ) with surfactant (beractant, $100 \mathrm{mg} / \mathrm{kg}$, $4 \mathrm{~mL} / \mathrm{kg}$ ) treatment decreased the incidence of BPD or mortality compared to surfactant $(100 \mathrm{mg} / \mathrm{kg})$ only treatment $(66 \%$ to $42 \%, p<0.001$ ). Also, levels of interleukins (IL-1, -6 , and -8 ) in tracheal aspirates were lower in budesonide with surfactant treatment group compared to those in surfactant only treatment group, indicating that budesonide could ameliorate inflammation. Physical growth and neurodevelopmental impairment were similar between the two groups in a follow up study at the age of two to three years of these enrolled preterm infants. Researchers reported that intratracheal administration of budesonide with surfactant decreased BPD or mortality without significantly increasing acute or longterm adverse effects.

The differences of this study from Yeh's studies ${ }^{20,21,36}$ are that we used different preparation of surfactant (calfactant in this study vs. beractant in Yeh's studies), and different concentration ratio of surfactant to budesonide (140:1 in this study vs. 100:1 in Yeh's studies).

We couldn't find differences in the BPD, mortality rate, $\mathrm{BPD}$ or mortality, ventilator duration, and high stage ROP between the two groups. There were decreasing trends of those parameters in the treatment group compared to the control group without statistical differences. Hospital stay was decreased in the treatment group compared to control group with statistical significance. It might be due to decreasing trends of BPD and ventilator duration in the treatment group. The limitation of this study is that the small number of enrolled patients to prove statistical differences.
In conclusion, early intratracheal administration of budesonide and surfactant in preterm infants with severe RDS might decrease BPD and mortality without disturbing surfactant function. Further prospective randomized controlled studies with different preparations of surfactants with a large number of preterm infants are required. To the best of our knowledge, this is the first study administering budesonide with calfactant in preterm infants having severe RDS.

The protocol of this study was reviewed and approved by the Institutional Review Board of Inje University Busan Paik Hospital. A waiver of consent was granted for chart review without patient contact.

\section{REFERENCES}

1. Jobe AH. Mechanisms of lung injury and bronchopulmonary dysplasia. Am J Perinatol 2016; 33: 1076-1078.

2. Wilson-Costello D, Walsh MC, Langer JC, et al; Eunice Kennedy Shriver National Institute of Child Health and Human Development Neonatal Research Network. Impact of postnatal corticosteroid use on neurodevelopment at 18 to 22 months' adjusted age: effects of dose, timing, and risk of bronchopulmonary dysplasia in extremely low birth weight infants. Pediatrics 2009; 123: e430-e437.

3. Watterberg KL; American Academy of Pediatrics. Committee on Fetus and Newborn. Policy statement--postnatal corticosteroids to prevent or treat bronchopulmonary dysplasia. Pediatrics 2010; 126: 800-808

4. Davidson LM, Berkelhamer SK. Bronchopulmonary dysplasia: chronic lung disease of infancy and longterm pulmonary outcomes. J Clin Med 2017; 6.

5. Committee on Fetus and Newborn. Postnatal corticosteroids to treat or prevent chronic lung disease in preterm infants. Pediatrics 2002; 109: 330338.

6. National Asthma Education and Prevention Program. Expert Panel Report: Guidelines for the diagnosis and management of asthma update on selected topics-2002. J Allergy Clin Immunol 2002; 110(Suppl 5): S141-S219.

7. Bassler D, Plavka R, Shinwell ES, et al; NEUROSIS Trial Group. Early inhaled budesonide for the prevention of bronchopulmonary dysplasia. N Engl J Med 2015; 373: 1497-1506. 
8. Nakamura T, Yonemoto N, Nakayama M, et al; The Neonatal Research Network. Early inhaled steroid use in extremely low birthweight infants: a randomised controlled trial. Arch Dis Child Fetal Neonatal Ed 2016; 101: F552-F556.

9. Mazela J, Polin RA. Aerosol delivery to ventilated newborn infants: historical challenges and new directions. Eur J Pediatr 2011; 170: 433-444.

10. Ricci F, Catozzi C, Ravanetti F, et al. In vitro and in vivo characterization of poractant alfa supplemented with budesonide for safe and effective intratracheal administration. Pediatr Res 2017; 82: 1056-1063.

11. Agassandian M, Mallampalli RK. Surfactant phospholipid metabolism. Biochim Biophys Acta 2013; 1831: 612-625.

12. Parra E, Perez-Gil J. Composition, structure and mechanical properties define performance of pulmonary surfactant membranes and films. Chem Phys Lipids 2015; 185: 153-175.

13. Perez-Gil J, Weaver TE. Pulmonary surfactant pathophysiology: current models and open questions. Physiology (Bethesda) 2010; 25: 132-141.

14. van't Veen A, Gommers D, Mouton JW, Kluytmans JA, Krijt EJ, Lachmann B. Exogenous pulmonary surfactant as a drug delivering agent: influence of antibiotics on surfactant activity. Br J Pharmacol 1996; 118: 593-598.

15. van't Veen A, Mouton JW, Gommers D, Lachmann B. Pulmonary surfactant as vehicle for intratracheally instilled tobramycin in mice infected with Klebsiella pneumoniae. Br J Pharmacol 1996; 119: 1145-1148.

16. Kharasch VS, Sweeney TD, Fredberg J, et al. Pulmonary surfactant as a vehicle for intratracheal delivery of technetium sulfur colloid and pentamidine in hamster lungs. Am Rev Respir Dis 1991; 144: 909-913.

17. Pham S, Wiedmann TS. Note: dissolution of aerosol particles of budesonide in Survanta, a model lung surfactant. J Pharm Sci 2001; 90: 98-104.

18. Huang LT, Yeh TF, Kuo YL, Chen PC, Chen CM. Effect of surfactant and budesonide on the pulmonary distribution of fluorescent dye in mice. Pediatr Neonatol 2015; 56: 19-24.

19. Jobe AH. 50 Years ago in The Journal of Pediatrics: Respiratory distress syndrome of newborn infants: I. Diagnosis and incidence Miller H. J Pediatr 1962; 61: 2-8. Respiratory Distress Syndrome of Newborn Infants: II. Clinical Study of Pathogenesis Miller H. J Pediatr 1962; 61: 9-16. J Pediatr 2012; 161: 93.
20. Yeh TF, Lin $\mathrm{HC}$, Chang $\mathrm{CH}$, et al. Early intratracheal instillation of budesonide using surfactant as a vehicle to prevent chronic lung disease in preterm infants: a pilot study. Pediatrics 2008; 121: e1310-e1318.

21. Kuo HT, Lin HC, Tsai CH, Chouc IC, Yeh TF. A follow-up study of preterm infants given budesonide using surfactant as a vehicle to prevent chronic lung disease in preterm infants. J Pediatr 2010; 156: 537541.

22. Fenton TR. A new growth chart for preterm babies: Babson and Benda's chart updated with recent data and a new format. BMC Pediatr 2003; 3: 13.

23. Kinsella JP, Greenough A, Abman SH. Bronchopulmonary dysplasia. Lancet 2006; 367: 1421-1431.

24. Stoll BJ, Hansen NI, Adams-Chapman I, et al; National Institute of Child Health and Human Development Neonatal Research Network Neurodevelopmental and growth impairment among extremely low-birth-weight infants with neonatal infection. JAMA 2004; 292: 2357-2365.

25. Miller-Larsson A, Mattsson H, Hjertberg E, Dahlback M, Tunek A, Brattsand R. Reversible fatty acid conjugation of budesonide. Novel mechanism for prolonged retention of topically applied steroid in airway tissue. Drug Metab Dispos 1998; 26: 623-630.

26. Tunek A, Sjodin K, Hallstrom G. Reversible formation of fatty acid esters of budesonide, an antiasthma glucocorticoid, in human lung and liver microsomes. Drug Metab Dispos 1997; 25: 1311-1317.

27. Shah SS, Ohlsson A, Halliday HL, Shah VS. Inhaled versus systemic corticosteroids for the treatment of chronic lung disease in ventilated very low birth weight preterm infants. Cochrane Database Syst Rev 2003: CD002057.

28. Shah SS, Ohlsson A, Halliday HL, Shah VS. Inhaled versus systemic corticosteroids for the treatment of chronic lung disease in ventilated very low birth weight preterm infants. Cochrane Database Syst Rev 2007: CD002057.

29. Shah SS, Ohlsson A, Halliday HL, Shah VS. Inhaled versus systemic corticosteroids for the treatment of chronic lung disease in ventilated very low birth weight preterm infants. Cochrane Database Syst Rev 2012: CD002057.

30. Fajardo C, Levin D, Garcia M, Abrams D, Adamson I. Surfactant versus saline as a vehicle for corticosteroid delivery to the lungs of ventilated rabbits. Pediatr Res 1998; 43 (4 Pt 1): 542-547. 
31. Chen CM, Fang CL, Chang CH. Surfactant and corticosteroid effects on lung function in a rat model of acute lung injury. Crit Care Med 2001; 29: 21692175.

32. Nimmo AJ, Carstairs JR, Patole SK, Whitehall J, Davidson K, Vink R. Intratracheal administration of glucocorticoids using surfactant as a vehicle. Clin Exp Pharmacol Physiol 2002; 29: 661-665.

33. Yang CF, Jeng MJ, Soong WJ, Lee YS, Tsao PC, Tang RB. Acute pathophysiological effects of intratracheal instillation of budesonide and exogenous surfactant in a neonatal surfactant-depleted piglet model. Pediatr Neonatol 2010; 51: 219-226.
34. Yang CF, Lin CH, Chiou SY, et al. Intratracheal budesonide supplementation in addition to surfactant improves pulmonary outcome in surfactant-depleted newborn piglets. Pediatr Pulmonol 2013; 48: 151-159.

35. Roberts JK, Stockmann C, Dahl MJ, et al. Pharmacokinetics of budesonide administered with surfactant in premature lambs: implications for Neonatal Clinical Trials. Curr Clin Pharmacol 2016; 11: 53-61.

36. Yeh TF, Chen CM, Wu SY, et al. Intratracheal administration of budesonide/surfactant to prevent bronchopulmonary dysplasia. Am J Respir Crit Care Med 2016; 193: 86-95. 